\title{
O uso de metodologias ativas de ensino-aprendizagem em pediatria: uma revisão narrativa
}

\author{
The use of active teaching-learning methodologies in pediatrics: a narrative review \\ Bárbara Caroline Dias Faria' (D) barbaradiascf@gmail.com \\ Clésio Gontijo do Amaral' ${ }^{1}$ (D) clesiogontijo@gmail.com
}

\section{RESUMO}

Introdução: O modelo tradicional de ensino médico possui uma ideia biocêntrica dos problemas de saúde, hipervalorizando os aspectos biológicos do paciente, sem considerar os demais aspectos envolvidos no processo saúde-doença. Esse método é centrado no professor, e o aluno atua como receptor passivo do conhecimento. Em contrapartida, nas metodologias ativas, o estudante possui papel ativo no processo de ensino-aprendizagem, construindo um conhecimento crítico e reflexivo.

Objetivo: Este estudo teve como objetivos analisar a importância das metodologias ativas no ensino de Pediatria I do curso de Medicina da Universidade Federal de Minas Gerais (UFMG) e propor adaptações que permitam a aplicação dessas metodologias no período de ensino remoto emergencial (ERE).

Método: Trata-se de uma revisão narrativa, com dados obtidos de forma independente pelos autores, por meio de busca abrangente e não sistemática no PubMed e na SciELO. Primeiro, realizaram-se a busca e a análise de dados das principais metodologias ativas, e, posteriormente, os achados foram aplicados à disciplina de Pediatria I do curso de Medicina da UFMG, incluindo suas adaptações para a implementação no ERE.

Resultados: Analisaram-se a problematização, a aprendizagem baseada em problemas e o fishbowl como recursos didáticos das metodologias ativas. Esses métodos reforçam a curiosidade, a autonomia, a motivação e as capacidades crítica e reflexiva do aluno. Ademais, promovem integração entre teoria e prática, incentivo do trabalho em equipe e estímulo para o estudante se conscientizar sobre os problemas sociais existentes.

Conclusão: Assim, o uso das metodologias ativas no ensino em Pediatria I possibilita alcançar os objetivos da disciplina, tanto no modo presencial quanto no ERE, e atingir as expectativas das diretrizes brasileiras sobre a formação médica.

Palavras-chave: Ensino; Aprendizado Ativo; Aprendizagem Baseada em Problemas; Pediatria; Educação Médica.

\begin{abstract}
Introduction: The traditional model of medical education has a biocentric perspective of health problems, overestimating biological aspects of the patient, without considering the other aspects involved in the health-disease process. This method is teacher-centered and the student acts as a passive recipient of knowledge. On the other hand, in active methodologies the student plays an active role in the teaching-learning process, building critical and reflective knowledge.
\end{abstract}

Objective: This study aims to analyze the importance of active methodologies in the teaching process of Pediatrics I on the Medicine course at the Federal University of Minas Gerais and to propose changes in these methodologies so they can be employed during the period of Emergency Remote Education (ERE).

Method: It is a narrative review, with data obtained independently by the authors through a broad and non-systematic search in PUBMED and SCIELO. Data on the main active methodologies were collected and analyzed, and the findings were subsequently applied to Pediatrics I, including their adaptation to implementation in the ERE.

Results: The problematization, problem-based learning and fishbowl methodologies were analyzed as didactic resources of active methodologies. These methods reinforce the student's curiosity, autonomy, motivation and critical and reflective thinking skills. Furthermore, they promote integration between theory and practice learning, encourage teamwork and encourage students to become aware of existing social problems.

Conclusion: Using active methodologies in the teaching process of Pediatrics I makes it possible to achieve the objectives of this discipline, both in faceto-face and remote learning, and reach the expectations of the Brazilian Guidelines on medical education.

Keywords: Teaching; Active Learning; Problem-Based Learning; Pediatrics; Medical Education.

${ }^{1}$ Universidade Federal de Minas Gerais, Belo Horizonte, Minas Gerais, Brasil.

Editora-chefe: Rosiane Viana Zuza Diniz

Editor associado: Roberto Zonato Esteves

Recebido em 19/10/20; Aceito em 10/03/21.

Avaliado pelo processo de double blind review. 


\section{INTRODUÇÃO}

As diversas transformações que ocorreram nos últimos anos afetaram diretamentea educação.Deacordo com Bauman', a modernidade sólida é caracterizada por possuir princípios duradouros, os quais são estáveis e permitem ser controlados. Em contrapartida, a atual modernidade, denominada por ele de modernidade líquida, surge com características opostas à fase sólida, sendo caracterizada por possuir uma enorme mutabilidade e imprevisibilidade acerca do mundo, assim como do conhecimento. Devido a essa dinâmica, a sociedade passa a exigir a formação de médicos autônomos, que saibam trabalhar em grupo, que partilhem suas conquistas e que estejam em constante formação ${ }^{2}$. Ademais, o processo educacional do estudante de Medicina deve estar bem articulado à prática médica para garantir um atendimento integral à população.

Entretanto, muitas universidades utilizam o modelo de currículo médico conhecido como flexneriano, o qual possui uma visão biocêntrica dos problemas de saúde, contribuindo para que a educação médica seja de caráter cientificista e pragmático ${ }^{3}$. Além disso, esse modelo biomédico oferece uma visão reducionista e fragmentada do paciente, desconsiderando os seus aspectos socioculturais ${ }^{4,5}$. Portanto, a formação desses profissionais da saúde é moldada com enfoque na atenção curativa, individualizada e unicausal da doença ${ }^{6}$, em que a saúde é compreendida como um estado ausente de doença, não existindo a preocupação com o estado físico e mental do paciente ${ }^{5}$.

Devido às problemáticas evidenciadas e às expectativas da sociedade em relação ao perfil médico, foram criadas, no Brasil, as Diretrizes Curriculares Nacionais (DCN) da saúde em $2001^{7}$, as quais ampliaram o conceito de educação ao realizarem melhorias na formação médica ${ }^{8}$, pois propuseram mudanças que incluíram as áreas socioculturais do estudante no processo de sua formação ${ }^{9}$. Ademais, a atualização das DCN feitas em 2014 reforçou a necessidade de um ensino capaz de formar médicos críticos, reflexivos e autônomos ${ }^{10}$. Nesse contexto, a possibilidade de o indivíduo tornar-se consciente em relação aos problemas sociais mostrou a importância de dar atenção a essas adversidades, além de contribuir para a sua aproximação ao Sistema Único de Saúde (SUS).

Nesse cenário, deve-se alterar o método de ensinoaprendizagem no ensino médico em Pediatria I para adequarse a essas transformações. Essa nova abordagem deve ser centralizada no estudante de Pediatria, permitindo que ele assuma uma postura ativa, crítica e reflexiva em seu processo de aprendizagem, de modo a ultrapassar a formação puramente técnica. Assim, o processo de ensino-aprendizagem será mais efetivo, contribuindo para a formação de médicos competentes e capazes de considerar o eixo biopsicossocial do paciente ${ }^{11}$.
Com base nessas considerações, o objetivo do presente estudo é abordar as principais metodologias ativas de ensinoaprendizagem, destacando seus pontos positivos e negativos. Objetiva-se também discutir a importância da utilização desses métodos tanto no modo presencial quanto no ensino remoto emergencial (ERE) e sugerir adaptações que permitam a aplicação dessas metodologias ativas no período de ERE na disciplina de Pediatria I da Universidade Federal de Minas Gerais (UFMG).

\section{MÉTODO}

Os dados foram obtidos de forma independente pelos autores por meio de uma busca abrangente e não sistemática nas bases eletrônicas de dados PubMed e SciELO, utilizando os descritores "metodologias ativas de ensino", "ensino-aprendizagem", "pediatria", "educação médica", "problematização", "aprendizagem baseada em problemas", "fishbowl", "ensino remoto emergencial". Os artigos foram revisados criticamente e selecionados pelos autores. Após seleção, leitura e análise crítica dos artigos, os autores analisaram detalhadamente três recursos didáticos das metodologias ativas de ensino que poderiam ser mais bem utilizadas na disciplina de Pediatria I: problematização, aprendizagem baseada em problemas (ABP) e fishbowl. Primeiro, realizaram-se a busca e a análise de dados dessas metodologias ativas, e, posteriormente, os achados foram aplicados à disciplina de Pediatria I do curso de Medicina da UFMG, incluindo as adaptações para a implementação e melhor aproveitamento no ERE.

\section{RESULTADOS}

\section{A disciplina de Pediatria I da UFMG}

A Pediatria I é muito importante para dar as bases ao aluno e direcioná-lo para uma boa formação no que concerne ao atendimento da criança. Na sua ementa ${ }^{12}$, destacam-se os fundamentos teóricos e práticos do atendimento pediátrico, com ênfase na semiologia de crianças e adolescentes, com o desenvolvimento das habilidades de comunicação, relação médico-paciente, ética médica, aspectos de relações humanas e étnico-raciais. Tem como princípio pedagógico o aprendizado centrado no aluno, em que o professor atua como facilitador, supervisiona o atendimento médico, orienta os estudos complementares específicos e estimula atitudes críticas em relação ao sistema de saúde vigente. Baseia-se nos princípios do "aprender fazendo" e "aprender a aprender".

\section{A importância das metodologias ativas no ensino médico}

De acordo com o artigo 198 da Constituição Federal brasileira de 1988, o SUS é organizado conforme algumas 
diretrizes, podendo destacar o atendimento integral, com prioridade para as atividades preventivas, sem prejuízo dos serviços assistenciais ${ }^{13}$.

Nesse cenário, visando garantir que o profissional da saúde seja capaz de fornecer esse atendimento integral, as DCN dos cursos de graduação na área de saúde estabelecem que o ensino médico deve compreender:

[...] perfil do egresso/profissional: médico, com formação generalista, humanista, crítica e reflexiva, capacitado a atuar, pautado em princípios éticos, no processo de saúde-doença em seus diferentes níveis de atenção, com ações de promoção, prevenção, recuperação e reabilitação à saúde, na perspectiva da integralidade da assistência, com senso de responsabilidade social e compromisso com a cidadania, como promotor da saúde integral do ser humano?.

Entretanto, o atual modelo de ensino médico, conhecido como modelo tradicional, não é capaz de subsidiar essa formação humanizada, crítica, reflexiva e integrativa, uma vez que, além de ser centrado no professor, proporciona uma hipervalorização do aspecto biológico e uma fragmentação do conhecimento, desconsiderando os demais aspectos que estão envolvidos no processo saúde-doença ${ }^{14}$. Essa metodologia conservadora, a qual possui forte influência do mecanicismo de inspiração cartesiano-newtoniana ${ }^{6}$, contribui para a formação de profissionais que tendem a não apresentar competências relacionadas à integralidade do cuidado prestado ao paciente.

Além disso, a centralização do ensino no professor permite que ele se considere especialista na disciplina que leciona e enxergue o aluno como um receptor passivo do conhecimento ${ }^{6}$. Essa posição de observador contribui para o desenvolvimento de um conhecimento superficial por parte dos alunos, sendo passível de memorização e reprodução, sem a necessária crítica e reflexão ${ }^{6}$. Freire ${ }^{15}$ reforça essa ideia ao definir que o modelo tradicional de ensino é um instrumento de depósito de conhecimento em um aluno vazio e acrítico.

A disciplina de Pediatria I da UFMG tem por finalidade capacitar o estudante Medicina na realização de um atendimento médico à criança e ao adolescente em nível de atenção de cuidados primários, com a visão integral da atenção à saúde, integrando os aspectos biológicos, psicológicos e sociais e as ações preventivas, curativas e restauradoras ${ }^{12}$. Visando solucionar os problemas apontados no presente artigo e garantir o alcance dos objetivos do ensino de Pediatria I, assim como de toda a prática médica, o modelo tradicional deve ser substituído por métodos de ensino inovadores, como as metodologias ativas de ensino.

Nessa nova abordagem de ensino, os papéis do docente e do discente se invertem, ocorrendo uma centralização do ensino no aluno, sendo possível criar um ambiente em que os alunos sejam capazes de avaliar crítica e reflexivamente o contexto social no qual estão inseridos, além de permitir a aproximação da teoria com a prática na formação médica. O professor deixa de ter um papel focado na transmissão tradicional do conhecimento e passa a atuar como um facilitador e mediador do processo ensino-aprendizagem ${ }^{16,17}$.

As exigências para os docentes tornam-se maiores. Já não é suficiente apenas dominar o conteúdo, também é preciso desenvolver habilidades não cognitivas, como o entusiasmo, a compaixão e o altruísmo ${ }^{18}$. O professor torna-se responsável por influenciar as atitudes, o comportamento e a ética dos estudantes de Medicina ${ }^{19}$, ajudando, por meio de uma abordagem biopsicossocial, a cultivar os valores exigidos pela profissão médica. Desse modo, as metodologias ativas de ensino se concentram em proporcionar ao aluno competências que o prepare para enfrentar os mais diversos cenários da prática médica ${ }^{20}$.

Conforme descrito por Freire ${ }^{15}$, a prática docente deve sempre reforçar a curiosidade, a autonomia e a capacidade crítica do discente. Ademais, o educando, em parceria com o educador, deve ser sujeito da construção e da reconstrução do conhecimento, isto é, o processo educativo deve ser realizado por meio da interação entre docente e discente ${ }^{15}$. Essa visão do autor reforça a importância do uso de metodologias ativas de ensino em Pediatria I, pois elas colocam o aluno como agente ativo do seu processo de aprendizagem.

Porfim, as metodologias ativas de ensino-aprendizagem abrangem muitos recursos didáticos. Entretanto, no presente estudo iremos abordar e descrever a problematização, ABP e o fishbowl.

\section{Metodologia da problematização}

A metodologia da problematização se destaca como uma ferramenta de ensino que pode ser utilizada em momentos oportunos e fundamenta-se nas proposições de Bordenave et al. ${ }^{11}$ e nos princípios de Freire ${ }^{15}$. Zanotto et al. ${ }^{21}$ discutem sobre a ação de problematizar em Freire, a qual destaca que o processo de problematização enfatiza o sujeito práxico, isto é, considera o contexto social do sujeito, buscando a explicação da sua própria realidade para transformá-la a partir disso. Nessa visão, essa abordagem metodológica é dotada de capacidade para mobilizar o potencial social, político e ético do estudante ${ }^{6}$.

Como metodologia de ensino, a problematização não requer grandes mudanças materiais para sua implementação. Entretanto, ela exige uma mudança de postura por parte do docente para a realização de um trabalho reflexivo com o aluno. Isso, de certo modo, coloca o professor diante de situações desconhecidas e inesperadas, fazendo com que ele, 
em parceria com os alunos, participe ativamente da construção do conhecimento e não só atue na reprodução deste. Ademais, com o estudo da problemática podem surgir outras questões sobre o tema, as quais podem não ter sido previstas pelo professor e pelos alunos, exigindo, portanto, uma capacidade de explorar essas outras informações que podem ter enorme importância na interpretação do problema ${ }^{22}$.

Nesse sentido, o diagrama denominado "Método do Arco" por Charles Maguerez e apresentado por Bordenave et al. ${ }^{11}$ está representado pela Figura 1 e descreve as cinco etapas que compõem o caminho didático da metodologia da problematização, sendo elas: observação da realidade, pontoschave, teorização, hipóteses de solução e aplicação à realidade.

Inicialmente, na observação da realidade, os professores devem orientar os alunos a observar, de forma atenta e crítica, a realidade acerca de uma temática preestabelecida ${ }^{23}$. O estudante já possui sua própria bagagem de conhecimento e, quando se aproxima da realidade e analisa as informações existentes nela, consegue relacionar ambos os conhecimentos, sendo capaz de formular uma problemática sobre o contexto social analisado ${ }^{23,24}$.

Na segunda etapa, denominada pontos-chave, os alunos refletem e apontam as possíveis causas da problemática. Após essa análise, os estudantes estabelecem os pontos-chave do problema, os quais deverão ser abordados para melhor compreensão da problemática encontrada na etapa anterior ${ }^{23}$.

Sequencialmente, a teorização compreende a fase em que os alunos buscam, em artigos, informações sobre o problema, considerando os pontos-chave já estabelecidos. Esses dados encontrados devem ser analisados crítica e reflexivamente sobre a relevância para a resolução da problemática ${ }^{23}$.

A etapa das hipóteses de solução acontece após uma ampla análise sobre o problema e permite que os alunos questionem sobre possíveis ações para solucioná-lo ${ }^{23}$.

A última etapa, a aplicação à realidade, possibilita colocar em prática as soluções sobre o problema que foram estabelecidas pelo aluno na etapa anterior, permitindo a intervenção dele na realidade observada para transformá-la ${ }^{23}$.

Para Berbel ${ }^{23}$, por meio do arco de Maguerez, a problematização permite o exercício da práxis, possibilitando uma articulação entre teoria e prática durante todo o processo de ensino-aprendizagem. Nessa abordagem, o aluno de Pediatria I estará apto para assumir uma postura de ação-reflexão-ação ${ }^{23}$, adquirindo um conhecimento capaz de considerar os determinantes sociais como fatores que influenciam diretamente as condições de saúde da população ${ }^{24}$.

Em suma, apesar de suas limitações e desafios, a metodologia da problematização é uma proposta que visa à mudança de mentalidade, exigindo de todos os envolvidos no
Figura 1. Arco de Maguerez

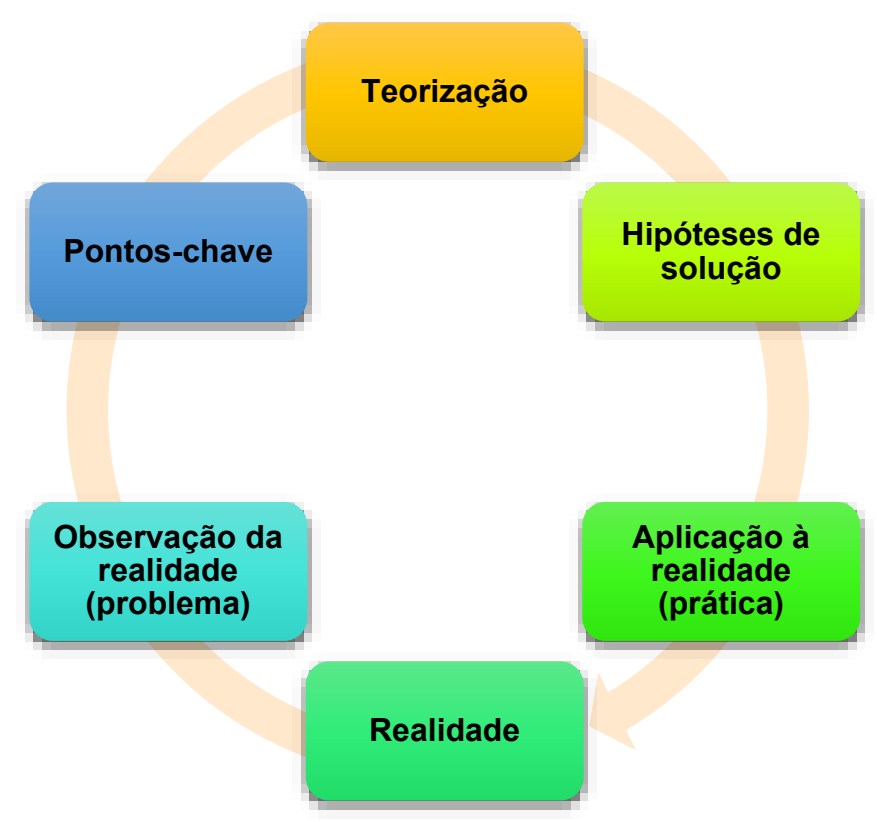

Fonte: Adaptada de Bordenave et al. ${ }^{11}$.

processo educativo a reavaliação de seus papéis para ressignificar o processo de ensino-aprendizagem ${ }^{22}$. Os pontos positivos e negativos da problematização estão descritos no Quadro 1.

\section{Aprendizagem baseada em problemas}

A ABP é centrada no discente e utiliza problemas ou situações da vida real com o propósito de estimular o desenvolvimento conceitual, procedimental e atitudinal do aluno $^{25}$. Essa abordagem pauta-se pelos fundamentos do filósofo norte-americano John Dewey, o qual destaca que os problemas devem ser capazes de gerar dúvidas, desequilíbrios ou perturbações intelectuais, possibilitando interações ativas com o conhecimento para que o aluno desenvolva uma aprendizagem significativa22.

$\mathrm{Na} A B P$, os discentes recebem um problema que precisa ser discutido no grupo tutorial. Para isso, são traçados objetivos a serem alcançados, e os alunos devem levantar hipóteses e, posteriormente, encontrar alternativas para a resolução desse problema. Os alunos são motivados a utilizar os seus conhecimentos prévios acerca do assunto e a fazer uma busca sobre a questão levantada, a fim de discutir, sintetizar e compartilhar os conhecimentos adquiridos ${ }^{22}$.

O grupo tutorial é composto, geralmente, por dez alunos e um tutor. Entre os alunos, deve haver um coordenador com o objetivo de facilitar a discussão no grupo e um secretário responsável por fazer anotação da discussão realizada. Por sua vez, o tutor é um membro do corpo docente e atua como mediador do processo de ensino-aprendizagem ${ }^{22}$. Os demais estudantes participam ativamente da discussão do problema. 
Para atingir os objetivos, o grupo tutorial possui setes passos básicos, os quais estão descritos na Figura 2.

Nesse cenário, além do conteúdo a ser aprendido, a ABP estimula o aluno a desenvolver habilidades para gerenciar o próprio aprendizado, trabalhar em grupo, buscar ativamente as informações, integrar o conhecimento e identificar e explorar áreas novas. Também permite maior interação entre teoria e prática, possibilitando ao estudante domínio do conhecimento específico, além do desenvolvimento de habilidades e atitudes profissionais s,22,25,26. $^{6}$.

Quadro 1. Pontos positivos e negativos dos métodos ativos de ensino-aprendizagem

\begin{tabular}{|c|c|c|}
\hline $\begin{array}{l}\text { Métodos ativos de } \\
\text { ensino-aprendizagem }\end{array}$ & Pontos positivos & Pontos negativos \\
\hline \multirow{5}{*}{ Problematização } & $\begin{array}{l}\text { Valorização do contexto social da situação } \\
\text { problema. }\end{array}$ & \multirow{2}{*}{$\begin{array}{l}\text { Deve ser utilizada apenas em momentos } \\
\text { específicos. }\end{array}$} \\
\hline & Transformação da realidade. & \\
\hline & $\begin{array}{l}\text { Incentivo ao potencial social, político e ético do } \\
\text { estudante. }\end{array}$ & $\begin{array}{l}\text { Requer mudança de comportamento de todos } \\
\text { os envolvidos no processo. }\end{array}$ \\
\hline & Postura de ação-reflexão-ação do estudante. & $\begin{array}{l}\text { O professor pode se encontrar diante de } \\
\text { situações desconhecidas e inesperadas. }\end{array}$ \\
\hline & $\begin{array}{l}\text { Ressignificação do processo de ensino- } \\
\text { aprendizagem. }\end{array}$ & $\begin{array}{l}\text { Podem surgir questões sobre o tema que não } \\
\text { foram previstas pelo professor e pelos alunos. }\end{array}$ \\
\hline \multirow{5}{*}{$\mathrm{ABP}$} & $\begin{array}{l}\text { Utiliza problemas ou situações da vida real. } \\
\text { Trabalho em grupo. }\end{array}$ & Falta de experiência dos professores. \\
\hline & $\begin{array}{l}\text { Gerenciamento do próprio aprendizado. } \\
\text { Integração entre teoria e prática. }\end{array}$ & $\begin{array}{l}\text { Resistência dos estudantes em abandonar a } \\
\text { postura passiva. }\end{array}$ \\
\hline & $\begin{array}{l}\text { Busca ativa dos estudantes por informações. } \\
\text { Flexibilidade de tempo. }\end{array}$ & $\begin{array}{l}\text { Requer investimentos em recursos humanos e } \\
\text { materiais. }\end{array}$ \\
\hline & $\begin{array}{l}\text { Maior autonomia, independência e } \\
\text { responsabilidade por parte do estudante. }\end{array}$ & Demanda maior e esforço e tempo do professor. \\
\hline & Trabalho em grupo. & Deixa os alunos nervosos e ansiosos. \\
\hline \multirow{3}{*}{ Fishbowl } & Encoraja a discussão e o pensamento pós-formal. & $\begin{array}{l}\text { As pessoas do círculo externo podem ficar } \\
\text { dispersas durante a discussão. }\end{array}$ \\
\hline & $\begin{array}{l}\text { Desenvolvimento de visão crítica e ponderada } \\
\text { da realidade. }\end{array}$ & \multirow{2}{*}{ Demanda maior e esforço e tempo do professor. } \\
\hline & $\begin{array}{l}\text { Estimula habilidades de comunicação entre } \\
\text { estudantes. }\end{array}$ & \\
\hline
\end{tabular}

Figura 2. Passos de um grupo tutorial.

\begin{tabular}{|l|l|}
\hline 1 & $\begin{array}{l}\text { - Leitura do problema e identificação e esclarecimento de termos } \\
\text { desconhecidos. }\end{array}$ \\
\hline 2 & - Identificação dos problemas propostos. \\
\hline 3 & - Formulação de hipóteses (brainstorming). \\
\hline 4 & - Resumo das hipóteses. \\
\hline 5 & - Formulação dos objetivos de aprendizagem. \\
\hline 6 & - Estudo individual dos objetivos de aprendizagem. \\
\hline 7 & - Rediscussão do problema ante os novos conhecimentos adquiridos. \\
\hline
\end{tabular}

Fonte: Adaptada de Borges et al. ${ }^{26}$. 
Segundo Sardo ${ }^{27}$, como a ABP possui mais flexibilidade de tempo e espaço para a realização das diferentes atividades previstas do que o modelo tradicional, os alunos têm maior autonomia, independência e responsabilidade pela própria formação. Ademais, um estudo analisado por Koh et al. ${ }^{28}$ mostrou que a implementação da ABP no curso de Medicina resultou em efeitos positivos no que se refere às competências do médico, especialmente nas dimensões social e cognitiva.

Contudo, a ABP possui algumas limitações que precisam ser destacadas. Muitos professores ainda não tiveram o devido treinamento para atuar nesse modelo de ensino e sentem dificuldades no processo de adaptação, sendo um dos principais obstáculos encontrados para adoção da $\mathrm{ABP}$ no ensino médico. Alguns estudantes também podem inicialmente mostrar desconforto e resistência em relação a essa quebra de passividade para a adoção de uma postura proativa na construção de seu conhecimento. Ademais, a implementação da ABP, diferentemente da problematização, requer investimentos em recursos humanos e materiais, como ampliação do corpo docente e investimento em bibliotecas, laboratórios e salas de estudo ${ }^{26}$.

Nesse sentido, a ABP possui pontos positivos e pontos negativos como os descritos no Quadro 1. Embora existam dificuldades e limitações, essa metodologia deve ser estimulada e implementada no ensino de Pediatria I. A ABP possibilitará que os discentes iniciem seus estudos com um caso clínico, em que o paciente apresenta um determinado problema, sendo papel do aluno investigar e solucionar a problemática apresentada. Nesse sentido, o estudante será estimulado a integrar conteúdos, desenvolver um raciocínio clínico, lidar com situações que possivelmente serão encontradas em sua prática clínica, além de sair de uma posição meramente passiva, com memorização de diagnósticos baseados em sinais e sintomas, para uma postura ativa, construindo ativamente sua aprendizagem. Ademais, a articulação dos conhecimentos prévios do aluno com o conhecimento de outros estudantes do grupo facilita o desenvolvimento do raciocínio crítico, habilidades de comunicação e entendimento da necessidade de aprender ao longo da vida ${ }^{29,30}$. Com isso, os discentes serão capazes de construir um conhecimento que passe por um processo indagativo e reflexivo, e que os habilite a aprender a aprender. Como resultado desse processo, eles se tornarão críticos e aptos a tomar decisões mais eficazes ${ }^{25}$.

\section{Fishbowl}

O fishbowl é uma técnica interativa e dinâmica utilizada para grupos pequenos, em que os participantes se organizam em dois círculos concêntricos. No círculo interno, os participantes discutem determinadas questões, de modo a contribuir para o desenvolvimento do tema. Por sua vez, o círculo externo é formado pelos observadores, os quais devem se organizar e ouvir ativamente ${ }^{31,32}$.

Há dois tipos de fishbowl: aberto e fechado. No fishbowl aberto, uma ou duas cadeiras do círculo interno ficam vazias para que os participantes observadores possam, a qualquer momento, se envolver na discussão. Para que isso funcione, um membro do círculo interno deverá sair voluntariamente quando a cadeira vazia for ocupada por outro membro, de modo a sempre deixar uma cadeira disponível, permitindo a continuidade da dinâmica. No fishbowl fechado, o facilitador divide os participantes em dois grupos, em que um grupo participa inicialmente do círculo interno, enquanto o outro grupo atua como observador. Posteriormente, os papéis se invertem ${ }^{31}$. A organização do fishbowl está ilustrada na Figura $3^{33}$.

O fishbowl é utilizado no ensino superior como uma ferramenta de aprendizagem capaz de encorajar a discussão e o pensamento pós-formal, pois promove interações que desafiam as opiniões dos estudantes sobre uma determinada questão. O pensamento pós-formal é o processo no qual o indivíduo torna-se capaz de valorizar opiniões equivalentes e diferentes, abandonando as visões extremas e absolutas, isto é, no preto e no branco ${ }^{34}$.

No caso da disciplina de Pediatria I, além de possibilitar uma visão mais crítica e ponderada da realidade, o fishbowl pode ser utilizado para o desenvolvimento de habilidades de comunicação e para o treinamento de anamnese. Para isso, um ou dois alunos do círculo interno devem conduzir uma consulta com a presença de um paciente simulado, sendo observados pelos estudantes do círculo externo e pelo facilitador ${ }^{32}$. No final

Figura 3. Representação do fishbowl.

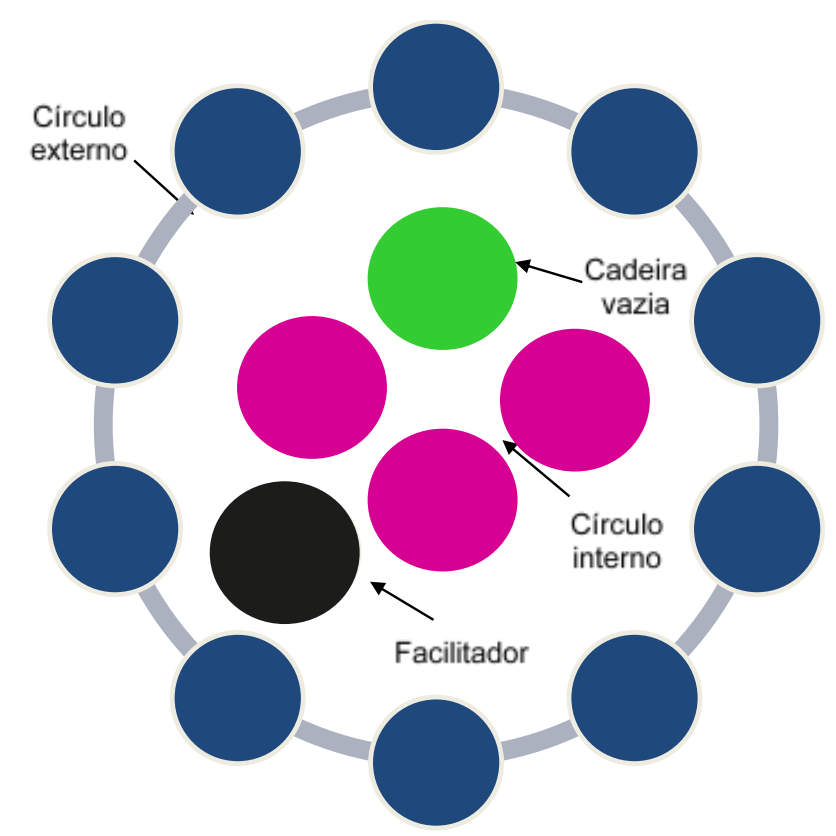

Fonte: Adaptada de Mucke et al. ${ }^{33}$. 
da dinâmica, é importante que os alunos recebam feedback do tutor, do paciente simulado e dos observadores ${ }^{32}$.

Por fim, o estudo realizado por Pearson et al. ${ }^{34}$ traz algumas limitações do fishbowl. Para os autores, os alunos ficam nervosos e ansiosos e não querem falar na frente da classe. Ademais, as pessoas do círculo interno estão sob uma pressão maior do que os alunos observadores, de modo que as pessoas de fora podem ficar dispersas durante a discussão ${ }^{34}$. Também é importante ressaltar que, por se tratar de uma metodologia ativa de ensino, o fishbowl consome muito tempo do docente no preparo, na aplicação e na avaliação das atividades ${ }^{35}$. O Quadro 1 ilustra os pontos positivos e negativos do fishbowl.

\section{Metodologias ativas no ensino remoto emergencial}

A atual situação pandêmica ocasionada pelo novo coronavírus provocou a suspensão de aulas presenciais de muitas instituições educacionais do Brasil, e o distanciamento social foi uma das ferramentas a serem adotadas para evitar a propagação rápida do vírus na sociedade ${ }^{36}$. Nesse contexto, muitas instituições de ensino adotaram o ERE como um modo de entrega alternativo em razão das circunstâncias da crise ${ }^{37}$.

Em contraste com a educação a distância (EaD), a qual preconiza a existência de uma infraestrutura para a sua oferta, o ERE surge como uma alternativa temporária de ensino para que as atividades acadêmicas, as quais seriam ministradas presencialmente ou de forma híbrida, não sejam interrompidas no período de crise. Assim, o termo remoto compreende ao distanciamento geográfico entre aluno e professor, enquanto o termo emergencial sinaliza o fato de que o planejamento pedagógico foi reinventado rapidamente ${ }^{38}$.

No contexto do ERE, as instituições, os professores e os alunos precisaram se adaptar e se reinventar para deslocar o ensino presencial para os meios digitais, visto que o distanciamento geográfico entre docente e discente pode reduzir questões como interesse, motivação e engajamento do aluno. Ademais, a adoção de práticas avaliativas baseadas na reflexão, construção, criatividade, parceria, autoavaliação e autonomia, referentes tanto ao trabalho do aluno quanto ao do professor, é um grande desafio desse novo formato de ensino $^{39}$. Desse modo, torna-se ainda mais importante inserir a aprendizagem ativa no ERE, visando estimular os alunos a adotar uma postura ativa do conhecimento, de modo a participar ativamente de todo o processo de seu ensino-aprendizagem, reduzindo essas adversidades encontradas.

A disciplina de Pediatria I, a qual possui uma carga horária de 90 horas totais, sendo 70 horas dedicadas às atividades práticas, vem enfrentando grandes desafios para garantir o alcance dos objetivos da disciplina de maneira efetiva nesse novo formato, que está sendo ofertado na plataforma Microsoft Teams. Uma possível solução dessas adversidades é a ampliação da utilização de metodologias ativas de ensino, fazendo adaptações necessárias e pertinentes à atual situação. Nessa abordagem, o papel interativo do docente com os alunos, atuando apenas quando é necessário, facilita o aprendizado e desvia o foco para que o estudante seja responsável pelo próprio conhecimento, passando a exercer atitude crítica e construtiva quando bem orientado ${ }^{35}$.

A metodologia da problematização, a ABP e o fishbowl, que foram discutidos no presente artigo, são ferramentas que podem ser utilizadas no ERE. Assim, a problematização possibilitará que o aluno de Pediatria I, durante o ERE, seja capaz de visualizar, de forma crítica e reflexiva, o contexto biopsicossocial do paciente, contribuindo para uma ressignificação do processo de adoecimento, bem como de sua prática médica. Além de permitirem ao estudante desenvolver a autonomia, inteligência relacional e responsabilidade sobre o autoaprendizado, a ABP e o fishbowl incentivam o trabalho em grupo, no qual são fundamentais a interação, o compartilhamento, o respeito à singularidade e a habilidade de lidar com o outro em sua totalidade, possibilitando uma aquisição progressiva de maturidade e autonomia ${ }^{35}$. Ademais, essas três metodologias de ensino-aprendizagem colocam o aluno como principal ator do processo de construção do conhecimento, possibilitam a integração entre os conteúdos e promovem a aproximação entre teoria e prática.

Portanto, o uso de metodologias ativas como ferramenta de ensino em Pediatria I no ERE possibilita maior alcance dos objetivos e do princípio pedagógico da disciplina nesse novo formato. Essas abordagens metodológicas fortalecerão a postura ativa, reflexiva e crítica do estudante de Pediatria I, permitindo que ele se sinta motivado a buscar a educação permanente, além de se tornar capaz de considerar os diversos contextos sociais que serão encontrados em sua prática médica, de forma a ser preparado para garantir um atendimento integral à população.

\section{Implementação das metodologias ativas no ERE da disciplina de Pediatria I}

Para que o uso das metodologias ativas de ensino no ERE seja mais efetivo, algumas adaptações devem ser realizadas. O Quadro 2 sintetiza possíveis medidas adaptativas para a implementação dessas abordagens metodológicas nesse novo formato de ensino. 
Quadro 2. Adaptações das metodologias ativas ao ERE.

\begin{tabular}{ll}
\hline Metodologias ativas & \multicolumn{1}{c}{ Adaptações ao ERE } \\
\hline \multirow{2}{*}{ Problematização } & Utilização em momentos oportunos e em assuntos específicos. \\
& Grupos de dez alunos. \\
& O docente deve apresentar para os discentes o problema a ser discutido na semana. \\
& Professor com papel de orientar no processo de ensino aprendizagem. \\
\hline & Grupos de dez alunos. \\
& Sorteio do aluno orientador e do aluno facilitador. \\
& Discutir casos clínicos baseados na temática da semana. \\
& Utilizar a ferramenta "levantar a mão" para entrar na discussão. \\
& O aluno orientador deve auxiliar na dinâmica da discussão. \\
& O professor deve guiar a discussão e incentivar o uso de termos semiotécnicos. \\
\hline & Grupos de dez alunos. \\
& Sorteio de um aluno para conduzir a consulta e de outro para ser o paciente. \\
& Na simulação da consulta, utilizar o fishbowl fechado. \\
& Encaminhar ao aluno-paciente o caso clínico para simulação. \\
& Uso de sons, imagens e vídeos para demonstração do exame físico. \\
& Ao final da consulta, abrir espaço para que os observadores entrem no círculo interno. \\
& Iniciar a segunda etapa com fishbowl aberto. \\
& Sortear três alunos. \\
& Todos os membros do círculo interno devem ativar a ferramenta “levantar a mão". \\
Utilizar a ferramenta "levantar a mão" para entrar no círculo interno e aguardar a saída voluntária \\
de algum membro.
\end{tabular}

\section{Problematização}

No contexto da disciplina de Pediatria I no ERE, a problematização deve ser utilizada a fim de garantir que o processo de ensino-aprendizado seja ativo, com a participação crítica e reflexiva dos estudantes. Tal metodologia deve ser utilizada em momentos oportunos, como na discussão sobre utilização de leite materno ou leite de vaca. Essa problematização, por exemplo, torna-se importante dado o fato de ser um assunto em que as mães geralmente apresentam dúvidas, sendo extremamente relevante que o aluno saiba aprender crítica e reflexivamente sobre essa temática. Assim, o ato de problematizar a discussão acerca do leite materno e do leite de vaca possibilitará que os alunos de Pediatria I tornem-se aptos a observar a realidade, formulando a problemática existente nesse contexto para que possam conseguir intervir adequadamente. Nesse sentido, para a utilização dessa metodologia no ERE, devem-se manter os subgrupos de dez alunos na disciplina de Pediatria I. O professor deve apresentar para os discentes a temática e o problema a ser discutido na semana, orientando-os nesse processo de ensino-aprendizagem.

\section{Aprendizagem baseada em problemas}

Nesse novo formato de ensino, a disciplina de Pediatria I pode utilizar a ABP para a discussão de casos clínicos, os quais serão inicialmente apresentados pelos professores e baseados na temática discutida na semana. Nesse cenário, deve-se manter a subturma de dez alunos, que inicialmente foram estabelecidos na disciplina de Pediatria I. O professor, o qual atuará como um mediador do processo de ensino-aprendizagem, deve elaborar um caso clínico e repassá-lo para os alunos. Dentre os alunos, devem ser selecionados um orientador e um secretário, os quais serão responsáveis por facilitar a discussão no grupo e fazer anotação da discussão realizada, respectivamente. 0 restante dos alunos deve participar ativamente da discussão do caso apresentado. Para que isso ocorra de maneira eficaz, a ABP precisa de algumas adaptações no ERE. Assim, ao ser apresentado o caso e iniciada a discussão, cada membro deve utilizar a ferramenta "levantar a mão" disponível na plataforma Microsoft Teams para sinalizar que deseja participar naquele instante. Ao fazer isso, o aluno orientador deve ficar atento às mãos levantadas e passar a palavra para o respectivo membro, permitindo uma dinâmica organizada. Os alunos devem discutir entre si sobre os casos, avaliando achados da anamnese e do exame físico, de modo a montar o raciocínio clínico sobre o caso apresentado. Além disso, o professor deve guiar e estimular os alunos a utilizar termos semiotécnicos adequados. 


\section{Fishbowl}

Para a implementação do fishbowl, deve-se manter a mesma subturma de dez alunos já preestabelecidos. Antes de cada aula, o professor deve sortear dois alunos: um será o responsável por conduzir a consulta, enquanto o outro atuará como paciente. Esses alunos sorteados farão parte do círculo interno, e o restante participará do círculo externo, e, nessa fase, recomenda-se a utilização do fishbowl fechado. Após o estabelecimento dos integrantes de cada círculo, o professor deve encaminhar ao aluno-paciente um caso clínico com dados específicos de sua queixa principal, bem como de todos os outros elementos que compõem a anamnese médica e o exame físico. A temática do caso clínico será baseada na programação do que será discutido na semana, como um caso sobre obesidade infantil na semana em que for trabalhado o tema alimentação. Além disso, o professor deve utilizar sons, vídeos e imagens para uma apresentação mais real e didática do exame físico.

No final da simulação da consulta, o professor, que atua como um facilitador do processo, deve abrir espaço para que os participantes inicialmente observadores possam, um de cada vez, assumir o papel de atendente, saindo do círculo externo para entrar no círculo interno. Com isso, esse grupo de observadores ganha espaço para atuar ativamente do processo. Em seguida, esgotadas todas as perguntas e condutas da anamnese e do exame físico, o facilitador deve sortear três alunos para entrarem no círculo interno, iniciando a discussão do caso clínico com base na análise de dados extraídos do paciente. Assim, nessa segunda etapa, pode-se utilizar o fishbowl aberto, em que há uma "cadeira livre" para que os participantes observadores possam, a qualquer momento, se envolver na discussão. Para isso acontecer, todos os alunos do círculo interno devem ativar a ferramenta "levantar a mão" disponível na plataforma Microsoft Teams, e, quando um aluno do grupo observador desejar entrar no círculo interno, ele deverá ativar essa ferramenta e aguardar a saída voluntária de um membro, de modo a permitir a continuidade da dinâmica. Nesse contexto, o fishbowl pode ser adaptado para o ERE, a fim de possibilitar a estimulação e o fechamento do raciocínio clínico em cima do caso discutido, estimulando um papel ativo de todos os alunos da subturma.

\section{CONCLUSÃO}

Diferentemente da abordagem tradicional, as metodologias ativas permitem que o processo educativo seja realizado por meio da interação entre docente e discente, na qual o aluno abandona o papel de receptor passivo do conhecimento e passa a atuar como agente ativo de seu processo de ensino-aprendizagem. Ademais, com o ensino centrado no aluno, essas abordagens inovadoras e formativas, além de possibilitarem o desenvolvimento de um conhecimento verdadeiro, estimulam a autonomia, a visão crítica e reflexiva do estudante, o trabalho em equipe e o entendimento da necessidade de aprender a aprender ao longo da vida.

Nesse cenário, destacam-se a problematização, a ABP e o fishbowl como ferramentas inovadoras que devem ser utilizadas no ensino da Pediatria I, tanto na forma presencial como no ERE. Essas ferramentas permitem fornecer ao aluno competências que o tornem apto a enfrentar os mais diversos cenários da prática médica ${ }^{19}$, de modo a ultrapassar a formação puramente técnica e ser capaz de considerar o eixo biopsicossocial do paciente, fornecendo um atendimento integralizado à população. Ademais, os resultados apresentados por esta revisão narrativa pretendem contribuir para que ferramentas de metodologias ativas, como a problematização, a ABP e o fishbowl, possam ser adaptadas e possibilitar melhorias na qualidade do ERE.

Infere-se, portanto, que, embora seja um desafio, a implementação das metodologias ativas no ensino da disciplina de Pediatria I, tanto no modo presencial quanto no ERE, pode garantir o alcance dos objetivos e princípios dessa disciplina, assim como as expectativas das DCN sobre a formação médica.

\section{CONTRIBUIÇÃO DOS AUTORES}

Bárbara Caroline Dias Faria contribuiu para a concepção e o desenho do estudo; a coleta, análise e interpretação de dados; a redação e revisão crítica do manuscrito; e a aprovação final da versão a ser publicada. Clésio Gontijo do Amaral contribuiu para a revisão crítica do manuscrito e aprovação final da versão a ser publicada.

\section{CONFLITO DE INTERESSES}

Os autores declaram não haver conflito de interesses neste estudo.

\section{FINANCIAMENTO}

Declaramos que não houve financiamento para a realização desta pesquisa.

\section{REFERÊNCIAS}

1. Porcheddu A. Zygmunt Bauman: entrevista sobre a educação. Desafios pedagógicos e modernidade líquida. Cad Pesqui. 2009; 39(137):661-84.

2. Behrens MA. O paradigma emergente e a prática pedagógica. 5a ed. Petrópolis: Vozes; 2013.

3. Sugita TH, Alfaia R, Lima FMLS, Naghettini, AV, Costa NMSC, Ribeiro MGF. Situação do ensino de pediatria e receptividade para implantação de metodologias ativas de ensino-aprendizagem sob perspectiva docentediscente. Congresso Internacional - PBL2010. São Paulo: Universidade de São Paulo, Rede Pan-Americana de Aprendizado Baseado em Problemas; 2010. 
4. Freire P. Pedagogia da esperança. São Paulo: Paz e Terra; 1997.

5. Abreu JRP. Contexto atual do ensino médico: metodologias tradicionais e ativas - necessidades pedagógicas dos professores e da estrutura das escolas [dissertação]. Porto Alegre: Universidade Federal do Rio Grande do Sul; 2009.

6. Mitre SM, Siqueira-Batista R, Girardi-de-Mendonça JM, Morais-Pinto NM, Meirelles CAB, Pinto-Porto $C$, et al. Metodologias ativas de ensino-aprendizagem na formação profissional em saúde: debates atuais. Cien Saude Colet. 2008;13(supl 2):2133-44 [acesso em 14 out 2020]. Disponível em: http://www.scielo.br/scielo.php?script=sci_ arttext\&pid=S1413-81232008000900018\&lng=en.

7. Brasil. Parecer CNE/CES no 1.133/2001, de 7 de agosto de 2001. Diretrizes Curriculares Nacionais dos Cursos de Graduação em Enfermagem, Medicina e Nutrição. Diário Oficial da União, Brasília; 3 out. 2001. Seção 1, p. 28-31.

8. da Costa MCG, Tonhom SFR, Fleur LN. Ensino e aprendizagem da prática profissional: perspectiva de estudantes de Medicina. Rev Bras Educ Med. 2016;40(2):245-53.

9. Almeida MJ. Diretrizes Curriculares Nacionais do curso de graduação em Medicina. In: Almeida MJ. Diretrizes Curriculares Nacionais para os cursos universitários da área da saúde. 2a ed. Londrina: Rede Unida; 2005. p.45-51.

10. Brasil. Resolução $n^{\circ} 3$, de 20 de junho de 2014. Institui Diretrizes Curriculares Nacionais do curso de Graduação em Medicina e dá outras providências. Diário Oficial da União, Brasília; 23 jun 2014. Seção 1, p. 2-11.

11. Bordenave JD, Pereira AM. Estratégias de ensino aprendizagem. 12a ed. Petrópolis: Vozes; 1991.

12. Departamento de Pediatria da Faculdade de Medicina da UFMG. Programa da Disciplina de Pediatria I [acesso em 14 out 2020]. Disponível em https:// www.medicina.ufmg.br/ped/wp-content/uploads/sites/30/2020/09/ EMENTA-PEDIATRIA-I.pdf.

13. Brasil. Constituição da República Federativa do Brasil. Diário Oficial da União, Brasília; 5 de out 1988. Seção 2, p. 119-20.

14. Gomes AP, Rego S. Transformação da educação médica: é possível formar um novo médico a partir de mudanças no método de ensinoaprendizagem? Rev Bras Educ Med. 2011;35(4):557-66.

15. Freire P. Pedagogia da autonomia. Saberes necessários à prática educativa. 25a ed. São Paulo: Paz e Terra; 2002.

16. Harden RM, Crosby J. AMEE Guide n' 20: The good teacher is more than a lecturer - the twelve roles of the teacher. Med Teach. 2000;22(4):334-47.

17. Zabalza MA. O ensino universitário: seu cenário e seus protagonistas. Porto Alegre: Artmed; 2004.

18. Cho CS, Ramanan RA, Feldman MD. Defining the ideal qualities of mentorship: a qualitative analysis of the characteristics of outstanding mentors. Am J Med. 2011;124(5):453-8 [acesso em 14 out 2020]. Disponível em: https://www.amjmed.com/article/S0002-9343(11)00008-8/fulltext.

19. Ray S. Role models. BMJ. 2010;340:c1572

20. Gal B, Rubio M, Iglesias E, González P. Evaluation of participatory teaching methods in undergraduate medical students' learning along the first academic courses. PLoS One. 2018;13(1):1-8.

21. Zanotto MAC, de Rose TMS. Problematizar a própria realidade: análise de uma experiência de formação contínua. Educação e Pesquisa. 2003;29(1):45-54 [acesso em 14 out 2020]. Disponível em: http://www. revistas.usp.br/ep/article/view/27897.

22. Cyrino EG, Toralles-Pereira ML. Trabalhando com estratégias de ensinoaprendizado por descoberta na área da saúde: a problematização e a aprendizagem baseada em problemas. Cad Saude Publica. 2004;20(3):7808 [acesso em 14 out 2020]. Disponível em: http://www.scielo.br/scielo. php?script=sci_arttext\&pid=S0102-311X2004000300015\&lng=en.
23. Berbel NAN. A metodologia da problematização em três versões no contexto da didática e da formação de professores. Revista Diálogo Educacional. 2012;12(35):103-120.

24. Villardi ML, Cyrino EG, Berbel NAN. A problematização em educação em saúde: percepções dos professores tutores e alunos. São Paulo:Unesp; 2015.

25. Borochovicius E, Tortella JCB. Aprendizagem baseada em problemas: um método de ensino-aprendizagem e suas práticas educativas. Ensaio: Aval Pol Públ Educ. 2014;22(83):263-94 [acesso em 14 out 2020]. Disponível em: https://www.scielo.br/scielo.php?pid=S010440362014000200002\&script=sci_abstract\&tlng=pt.

26. Borges MC, Chachá SGF, Quintana SM, de Freitas LCC, Rodrigues MLV. Aprendizado baseado em problemas. Medicina (Ribeirão Preto). 2014;47(3):301-7 [acesso em 14 out 2020]. Disponível em: http://www. revistas.usp.br/rmrp/article/view/86619.

27. Sardo PMG. Aprendizagem baseada em problemas em reanimação cárdiopulmonar no ambiente virtual de aprendizagem Moodle [dissertação]. Florianópolis: Universidade Federal de Santa Catarina; 2007.

28. Koh GCH, Khoo HE, Wong ML, Koh D. The effects of problem-based learning during medical school on physician competency: a systematic review. CMAJ. 2008;178(1):34-41.

29. Gomes R, Brino RF, Aquilante AG, de Avó LRS. Aprendizagem baseada em problemas na formação médica e o currículo tradicional de Medicina: uma revisão bibliográfica. Rev Bras Educ Med. 2009;33(3):433-40.

30. Barrows HS, Tamblyn RM. Problem-based learning: an approach to medical education. New York: Springer; 1980.

31. Bryant $L$. The art of active listening. Pract Nurse. 2009;37(6):49-52 .

32. Sutherland RM, Reid K, Kok D, Collins M. Teaching a fishbowl tutorial: Sink or swim? Clin Teach. 2012;9(2):80-4.

33. Mucke J, Anders HJ, Aringer M, Chehab G, Fischer-Betz R, Hiepe F, et al. Swimming against the stream: the fishbowl discussion method as an interactive tool for medical conferences: experiences from the 11th European Lupus Meeting. Ann Rheum Dis. 2019;78(5):713-4.

34. Pearson SC, Eddlemon T, Kirkwood M, Pate A. Are fishbowl activities effective for teaching pharmacotherapy and developing postformal thought in pharmacy students? A pilot study. Curr Pharm Teach Learn. 2018 June 6;10(8):1070-5. doi: 10.1016/j.cptl.2018.05.009.

35. Souza CS, Iglesias AG, Pazin-Filho A. Estratégias inovadoras para métodos de ensino tradicionais - aspectos gerais. Medicina (Ribeirão Preto). 2014;47(3):284-92 [acesso em 14 out 2020]. Disponível em: http://www. revistas.usp.br/rmrp/article/view/86617.

36. Wilder-Smith A, Freedman DO. Isolation, quarantine, social distancing and community containment: pivotal role for old-style public health measures in the novel coronavirus (2019-nCoV) outbreak. J Travel Med 2020;27 (2).

37. Hodges $C$, Trust T, Moore S, Bond A. The difference between emergency remote teaching and online learning. Educause Review. 2020;2:112 [acesso em 14 out 2020]. Disponível em: https://er.educause.edu/ articles/2020/3/the-difference-between-emergency-remote-teachingand-online-learning.

38. Universidade Federal do Rio Grande do Sul. O ensino remoto emergencial e a educação à distância. UFRGS; 6 jul 2020 [acesso em 14 out 2020]. Disponivel em: https://www.ufrgs.br/coronavirus/base/artigo-o-ensinoremoto-emergencial-e-a-educacao-a-distancia/.

39. Universidade Federal de Minas Gerais. Ensino remoto emergencial (ERE) nos cursos de graduação da UFMG [acesso em 14 out 2020]. Disponível em: https://www2.ufmg.br/prograd/prograd/Pro-Reitoria-de-Graduacao/ Publicacoes/Ensino-Remoto-Emergencial. 